\title{
Expression of hypoxia-inducible factor-1 $\alpha$ affects tumor proliferation and antiapoptosis in surgically resected lung cancer
}

\author{
CHIHIRO TAKASAKI $^{1}$, MASASHI KOBAYASHI ${ }^{1}$, HIRONORI ISHIBASHI $^{1}$, \\ TAKUMI AKASHI ${ }^{2}$ and KENICHI OKUBO ${ }^{1}$
}

\author{
Departments of ${ }^{1}$ Thoracic Surgery and ${ }^{2}$ Pathology, Tokyo Medical and Dental University, Tokyo 113-0034, Japan
}

Received March 15, 2016; Accepted May 26, 2016

DOI: $10.3892 / \mathrm{mco} .2016 .937$

\begin{abstract}
Hypoxia-inducible factor (HIF)-1 is a transcription factor that allows cells to adapt to hypoxic situations. HIF-1 is known to control tissue proliferation, antiapoptosis, angiogenesis and glucose metabolism. Furthermore, HIF-1 is involved in the growth of numerous cancer types. The present study aimed to examine the expression of HIF-1 $\alpha$ immunohistochemically in resected lung cancers. The present study included 216 consecutive patients with lung cancer who underwent resection between April 2013 and January 2015. The patients' clinicopathological data were summarized, including imaging findings, tumor pathological characteristics, and the patient's age, sex and smoking status. The intratumoral expression of HIF- $1 \alpha$, survivin, c-Myc and the Ki-67 proliferation index were evaluated immunohistochemically. The patients were divided into two groups, according to the expression of HIF-1 $\alpha$ (low vs. high) and the clinicopathological characteristics of these groups were compared. It was revealed that HIF-1 $\alpha$ expression was significantly associated with ground glass opacity ratio, maximum standardized uptake value index, histological type (squamous cell carcinoma), differentiation and lymphatic invasion. Regarding the immunohistochemical findings, HIF-1 $\alpha$ expression was significantly correlated with the expression levels of c-Myc $(\mathrm{P}<0.01)$ and survivin $(\mathrm{P}<0.01)$. Furthermore, the Ki-67 proliferation index was significantly higher in high-HIF-1 $\alpha$ tumors compared with in low-HIF-1 $\alpha$ tumors $(\mathrm{P}=0.01)$. The multivariate analysis identified squamous cell carcinoma, high SUVmax and lymphatic invasion as significant and independent factors for high HIF-1 $\alpha$ expression. In conclusion, HIF-1 was highly expressed in certain
\end{abstract}

\begin{abstract}
Correspondence to: Professor Kenichi Okubo, Department of Thoracic Surgery, Tokyo Medical and Dental University, 1-5-45 Yushima Bunkyo-Ku, Tokyo 113-0034, Japan

E-mail: okubo.thsr@tmd.ac.jp
\end{abstract}

Abbreviations: GGO, ground glass opacity; HIF-1, hypoxia-inducible factor-1; VHL, von hippel-lindau

Key words: lung cancer, hypoxia-inducible factor-1 $\alpha$, immunohistochemistry, survivin, c-Myc subgroups of lung cancer with specific histopathology and images. HIF-1 $\alpha$ expression was associated with tumor proliferation and antiapoptosis in lung cancer.

\section{Introduction}

Oxygen is essential for aerobic organisms and a lack of oxygen results in considerable stresses to these organisms. Cells have a variety of hypoxia response mechanisms to counter hypoxic stress. The gene, hypoxia-inducible factor $(H I F)-1$, serves an important role in many of these mechanisms (1-7). The HIF-1 protein is a complex of HIF- $1 \alpha$ and HIF- $1 \beta$. HIF- $1 \beta$ is present constitutively within the cell nucleus. By contrast, HIF- $1 \alpha$ is present in the cytoplasm under normoxic conditions, and it promptly binds to the von Hippel-Lindau (VHL) protein and is decomposed by the ubiquitin proteasome system. In hypoxic conditions, HIF-1 $\alpha$ is unable to bind to the VHL protein in the cytoplasm, escapes decomposition and enters the nucleus. In the nucleus, it combines with HIF-1 $\beta$ to form the HIF-1 complex, which binds to DNA and acts as a transcription factor. HIF-1 assists in the activation of genes involved in angiogenesis, glycolysis, tumor proliferation and other associated pathways (1-7).

Solid cancers generally grow very rapidly and these tumors often face a shortage of oxygen since tumor angiogenesis is slower than growth. Therefore, numerous cancer types use the HIF-1 complex to adapt to hypoxia (1-3). A previous study reported that HIF-1 $\alpha$ expression was associated with tumor proliferation, antiapoptosis, angiogenesis, glycolysis and patient prognosis (4-7).

Few studies have examined HIF-1 $\alpha$ expression in surgically resected lung cancer $(8,9)$. Accordingly, the present study decided to perform a comprehensive clinicopathological study of the intratumoral expression of HIF-1 $\alpha$ in resected lung cancers, investigating the associations between HIF-1 $\alpha$ expression, other tumor malignancy indicators [survivin (10-15) and c-Myc (16-18)] and the clinicopathological features of the patients.

\section{Patients and methods}

Patients. The present study included 216 consecutive patients with lung cancer who underwent a pulmonary resection at Tokyo Medical and Dental University Hospital (Tokyo, 
Japan) between April 2013 and January 2015. The histological tumor classification was based on the $7^{\text {th }}$ lung cancer tumor node metastasis classification and the staging system proposed by the International Union Against Cancer (19). The clinical records and histological examination results of all patients were fully documented. High-resolution computed tomography was performed in all patients within 1 month prior to resection. The ground glass opacity (GGO) ratio was calculated in a lung window using the following formula: (1 - solid tumor size / GGO size) x100. Positron emission tomography was performed in 176 patients $(82.2 \%)$ and the maximum standardized uptake value (SUVmax) of the tumor was measured in these patients. Patients who received chemotherapy or radiotherapy prior to resection were excluded. The study was approved by the Ethics Committee of Tokyo Medical and Dental University Hospital and informed consent was obtained from each patient.

Immunohistochemical analysis. The antibodies used for immunohistochemical analysis were mouse monoclonal anti-Ki-67 (MIB-1; cat. no. M7240; Dako Denmark A/S, Glostrup, Denmark; 1:100), mouse monoclonal anti-survivin (D-8; cat. no. sc-17779; Santa Cruz Biotechnology, Inc., Santa Cruz, CA, USA; 1:50), mouse monoclonal anti-c-Myc (9E10; cat.no. sc-40; Santa Cruz Biotechnology, Inc.; 1:100) and mouse monoclonal anti-HIF-1 $\alpha$ (H1 alpha 67; cat. no. NB100-105; Novus Biologicals, Littleton, CO, USA; 1:50). Formalin-fixed paraffin-embedded tissues were cut into $4 \mu \mathrm{m}$ sections and mounted onto coated slides. Following deparaffinization and rehydration, the slides were heated in a microwave (10 min for Ki-67, $25 \mathrm{~min}$ for survivin, $5 \mathrm{~min}$ for c-Myc and $30 \mathrm{~min}$ for HIF- $1 \alpha)$ in a citrate buffer solution $(10 \mu \mathrm{mol} / \mathrm{l})$ at $\mathrm{pH}$ 6.0. After quenching the endogenous peroxidase activity with $0.3 \% \mathrm{H}_{2} \mathrm{O}_{2}$ for $30 \mathrm{~min}$, the sections were treated with $5 \%$ bovine serum albumin (Sigma-Aldrich, St. Louis, MO, USA). Duplicate sections were incubated overnight with the corresponding primary antibody. The sections were subsequently incubated with the avidin-biotin-peroxidase complex (Vector Laboratories, Burlingame, CA, USA) for $30 \mathrm{~min}$ and antibody binding was visualized with 3,3'-diaminobenzine tetrahydrochloride. The tissue sections were counterstained with Mayer's hematoxylin.

The immunostained sections were examined by two authors (Chihiro Takasaki and Masashi Kobayashi), in a blinded manner. At least 200 tumor cells were scored per field under $\mathrm{x} 40$ magnification. The percentages of tumor cells with positive staining for Ki-67, survivin, c-Myc and HIF-1 $\alpha$ were determined (Fig. 1). Discrepancies were jointly re-evaluated until a consensus was reached.

Statistical analysis. The statistical analysis was performed using StatView-J Software (version 5.0; SAS Institute Inc., Cary, NC, USA). Based on previous reports $(8,9,20)$, all samples were divided into two groups: A high-HIF-1 $\alpha$ tumor group, in which the percentage of HIF-1 $\alpha$-positive cells was $\geq 20 \%$, and a low-HIF-1 $\alpha$ tumor group, in which the percentage of HIF-1 $\alpha$-positive cell was $<20 \%$. The $\chi^{2}$-test was used to assess the association between HIF-1 $\alpha$ expression and categorical variables, including patient gender, smoking habits, pathological tumor stage, histological tumor type, vascular invasion, tumor differentiation and SUVmax (The tumor sample was considered to have a high SUVmax if the SUVmax was >5.0.). The t-test was used to assess the association between HIF-1 $\alpha$ expression and continuous variables, including patient age, tumor size, GGO ratio, Ki-67 proliferation index, survivin expression and c-Myc expression. All continuous variables were summarized in terms of their means and standard deviations. When investigating the association between the Ki-67 proliferation index and the survivin and c-Myc expression in the tumors, the sample was divided into two groups according to the rates of survivin and c-Myc expression, as follows: The sample was classified as a nuclear survivin-high tumor if the percentage of nuclear survivin-positive cells was $\geq 17 \%$ and the tumor was classified as a c-Myc-high tumor if the percentage of c-Myc-positive cells was $\geq 40 \%$. These thresholds were selected as they had the highest significance values in relation to the Ki-67 proliferation index (21).

A multivariate analysis using a logistic regression model was performed to determine the independent factors for high HIF-1 $\alpha$ expression. All statistical tests were two-tailed and $\mathrm{P}<0.05$ was considered to indicate a statistically significant difference.

\section{Results}

Patient characteristics. The characteristics of the patients are presented in Table I. The study included 216 patients with resected lung cancer, of whom 54 had squamous cell carcinoma $(25.0 \%)$ and 162 had non-squamous cell carcinoma (75\%), including adenocarcinoma, adenosquamous cell carcinoma, large cell carcinoma, large cell neuroendocrine carcinoma, and small cell carcinoma. With respect to tumor differentiation, 148 patients had $\geq \mathrm{G} 2$-grade disease and 68 patients had G1-grade disease.

Clinical significance of $H I F-1 \alpha$ expression. The immunohistochemical staining for HIF-1 $\alpha$ revealed a nuclear pattern (Fig. 1). Among the 216 tumors, the mean percentage of HIF-1 $\alpha$-positive cells was $14.6 \pm 24.3 \%$. Based on the $20 \%$ threshold for high HIF-1 $\alpha, 58$ (26.9\%) high-HIF-1 $\alpha$ tumors and $158(73.1 \%)$ low-HIF-1 $\alpha$ tumors were observed.

Regarding the patients' clinical characteristics, no significant associations between patient age, gender, smoking index, and HIF-1 $\alpha$ expression were observed. With respect to the preoperative imaging findings, the mean GGO ratios were $8.9 \pm 21.0 \%$ for high-HIF- $1 \alpha$ tumors and $19.0 \pm 30.0 \%$ for low-HIF-1 $\alpha$ tumors; the GGO ratio was significantly lower for high-HIF-1 $\alpha$ tumors compared with for low-HIF-1 $\alpha$ tumors $(\mathrm{P}=0.02$; Table II). The rate of tumors with high SUVmax was significantly greater in the high-HIF-1 $\alpha$ tumor group compared with that in the low-HIF-1 $\alpha$ tumor group $(\mathrm{P}<0.01$; Table II).

Regarding the tumors' pathological features, the rate of squamous cell carcinoma was significantly higher in the high-HIF-1 $\alpha$ tumors compared with that in the low-HIF-1 $\alpha$ tumors $(\mathrm{P}<0.01$; Table II). The lymphatic invasion rate was also significantly higher in the high-HIF-1 $\alpha$ tumors compared with in low-HIF-1 $\alpha$ tumors $(\mathrm{P}=0.03$; Table II). With respect to tumor differentiation, low-grade $(\geq \mathrm{G} 2)$ tumors had a significant association with high-HIF-1 $\alpha$ tumors. No association was observed between pathological stage and HIF-1 $\alpha$ expression. 
Table I. Patient characteristics.

\begin{tabular}{|c|c|c|}
\hline Characteristic & No. patients & $(\%)$ \\
\hline Total & 216 & 100.0 \\
\hline \multicolumn{3}{|l|}{ Age, years } \\
\hline Median & 72 & - \\
\hline Range & $39-89$ & - \\
\hline \multicolumn{3}{|l|}{ Gender } \\
\hline Male & 138 & 63.9 \\
\hline Female & 78 & 36.1 \\
\hline \multicolumn{3}{|l|}{ Smoking status } \\
\hline Non-smoker $(\mathrm{BI} \leq 100)$ & 53 & 24.5 \\
\hline Smoker & 163 & 75.5 \\
\hline \multicolumn{3}{|l|}{ Pathological tumor stage } \\
\hline IA & 92 & 42.6 \\
\hline IB & 55 & 25.5 \\
\hline IIA & 17 & 7.9 \\
\hline IIB & 14 & 6.5 \\
\hline IIIA & 36 & 16.6 \\
\hline IIIB & 0 & 0.0 \\
\hline IV & 2 & 1.0 \\
\hline \multicolumn{3}{|l|}{ Histological tumor type } \\
\hline Squamous & 54 & 25.0 \\
\hline Non-squamous & 162 & 75.0 \\
\hline \multicolumn{3}{|l|}{ Lymphatic invasion } \\
\hline+ & 38 & 17.6 \\
\hline- & 178 & 82.4 \\
\hline \multicolumn{3}{|l|}{ Venous invasion } \\
\hline+ & 108 & 50.0 \\
\hline- & 108 & 50.0 \\
\hline \multicolumn{3}{|l|}{ Tumor size (mm) } \\
\hline Median & 31 & - \\
\hline Range & $9-82$ & - \\
\hline \multicolumn{3}{|l|}{ GGO ratio $(\%)$} \\
\hline Median & 16.3 & - \\
\hline Range & $0-100$ & - \\
\hline \multicolumn{3}{|l|}{ SUVmax } \\
\hline Median & 4.4 & - \\
\hline Range & $0-27$ & - \\
\hline \multicolumn{3}{|l|}{ Tumor differentiation } \\
\hline G1 & 58 & 28.2 \\
\hline$\geq \mathrm{G} 2$ & 148 & 71.8 \\
\hline
\end{tabular}

BI, brinkman index; GGO, ground glass opacity; SUVmax, maximum standardized uptake value.

The multivariate logistic regression analysis identified squamous cell carcinoma $(\mathrm{P}=0.0009)$, lymphatic invasion $(\mathrm{P}=0.0350)$, and high SUVmax $(\mathrm{P}=0.0471)$ as significant and independent factors for high HIF-1 $\alpha$ expression in patients with lung cancer.
Table II. Association between HIF-1 $\alpha$ expression and the clinicopathological characteristics.

\begin{tabular}{|c|c|c|c|}
\hline \multirow[b]{2}{*}{ Characteristic } & \multicolumn{2}{|c|}{$\begin{array}{c}\text { HIF-1 } \alpha \\
\text { expression }\end{array}$} & \multirow[b]{2}{*}{ P-value } \\
\hline & High & Low & \\
\hline Mean age (years) & 70.8 & 70.0 & 0.56 \\
\hline \multicolumn{4}{|l|}{ Gender (n) } \\
\hline Male & 39 & 99 & 0.64 \\
\hline Female & 19 & 59 & \\
\hline \multicolumn{4}{|l|}{ Smoking status (n) } \\
\hline Non-smoker & 12 & 41 & 0.54 \\
\hline Smoker & 46 & 117 & \\
\hline \multicolumn{4}{|c|}{ Pathological tumor stage (n) } \\
\hline I & 38 & 109 & 0.75 \\
\hline$\geq \mathrm{II}$ & 20 & 49 & \\
\hline \multicolumn{4}{|c|}{ Histological tumor type (n) } \\
\hline Squamous & 27 & 27 & $<0.01$ \\
\hline Non-squamous & 31 & 131 & \\
\hline \multicolumn{4}{|l|}{ Lymphatic invasion (n) } \\
\hline+ & 16 & 22 & 0.03 \\
\hline- & 42 & 136 & \\
\hline \multicolumn{4}{|l|}{ Venous invasion (n) } \\
\hline+ & 35 & 73 & 0.09 \\
\hline- & 23 & 85 & \\
\hline Mean tumor size (mm) & 33.4 & 30.2 & 0.18 \\
\hline Mean GGO ratio (\%) & 8.9 & 19.0 & 0.02 \\
\hline \multicolumn{4}{|l|}{ SUVmax (n) } \\
\hline$\geq 5$ & 30 & 50 & $<0.01$ \\
\hline$<5$ & 17 & 79 & \\
\hline \multicolumn{4}{|l|}{ Tumor differentiation (n) } \\
\hline G1 & 9 & 49 & 0.03 \\
\hline$\geq \mathrm{G} 2$ & 47 & 101 & \\
\hline
\end{tabular}

HIF- $1 \alpha$, hypoxia-inducible factor- $1 \alpha$; GGO, ground glass opacity; SUVmax, maximum standardized uptake value.

Associations between the expression levels of HIF-1 $\alpha$, survivin and $c-M y c$, and the Ki-67 proliferation index. Immunohistochemical staining for survivin revealed a nuclear and/or cytoplasmic pattern (Fig. 1). The mean percentage of nuclear survivin-positive tumor cells was $13.7 \pm 20.3 \%$ and that of cytoplasmic survivin-positive tumor cells was $31.8 \pm 36.9 \%$. The nuclear survivin expression was significantly higher in the high-HIF-1 $\alpha$ tumors compared with in the low-HIF-1 $\alpha$ tumors (20.3 \pm 25.3 vs. $11.2 \pm 17.7 \%$; $\mathrm{P}<0.01$; Table III; Fig. 2$)$. No difference in HIF-1 $\alpha$ expression was observed according to cytoplasmic survivin.

Immunohistochemical staining for c-Myc revealed a cytoplasmic pattern following staining (Fig. 1). The mean percentage of c-Myc-positive tumor cells was $39.8 \pm 38.8 \%$ among all included tumors. c-Myc expression was signifi- 

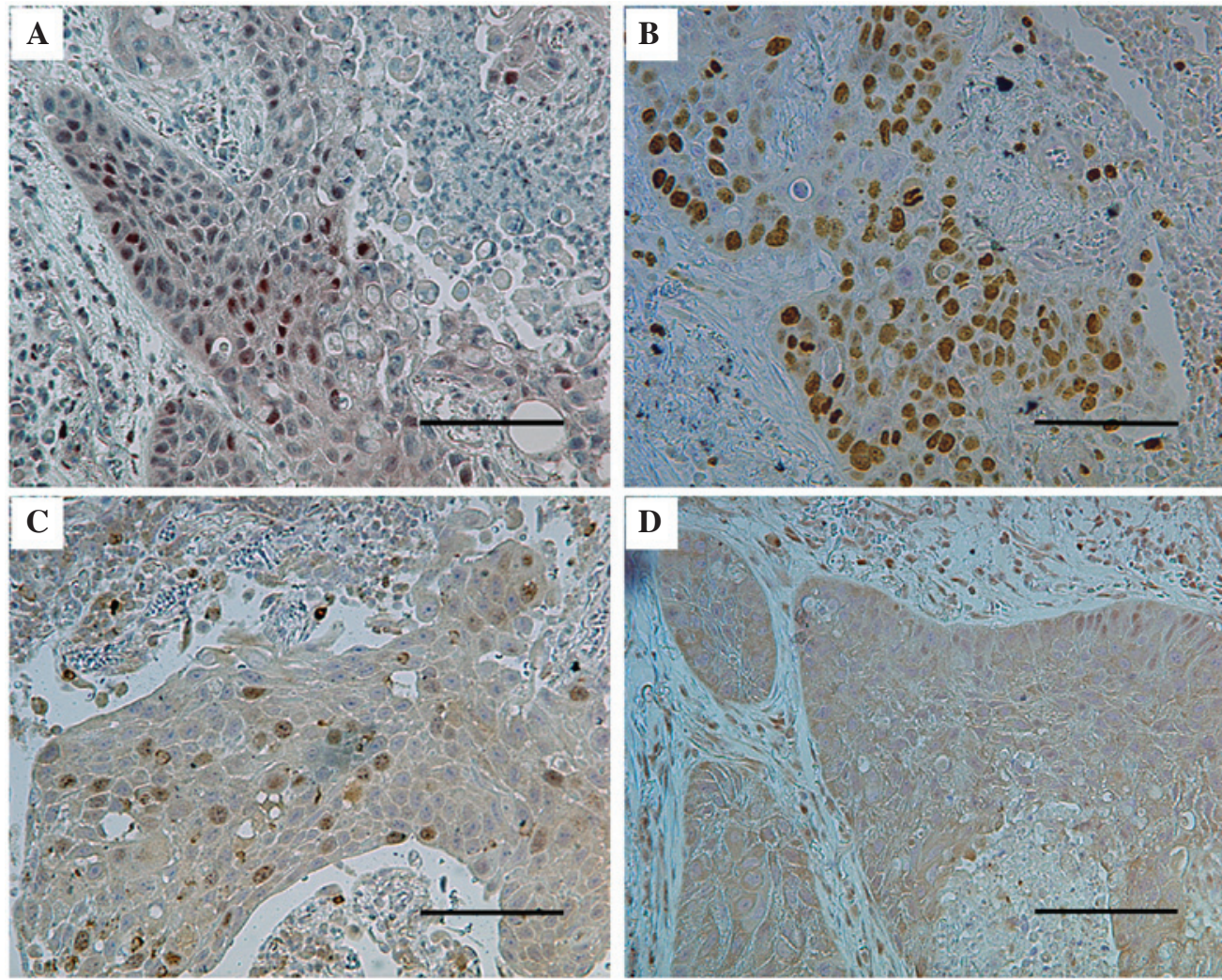

Figure 1. Representative immunohistochemistry findings for a lung tumor. A lung cancer tumor with positive nuclear staining for (A) hypoxia-inducible factor-1 $\alpha$, (B) Ki-67 and (C) survivin, as well as positive cytoplasmic staining for (D) c-Myc (scale bar, $200 \mu \mathrm{m}$ ).

A

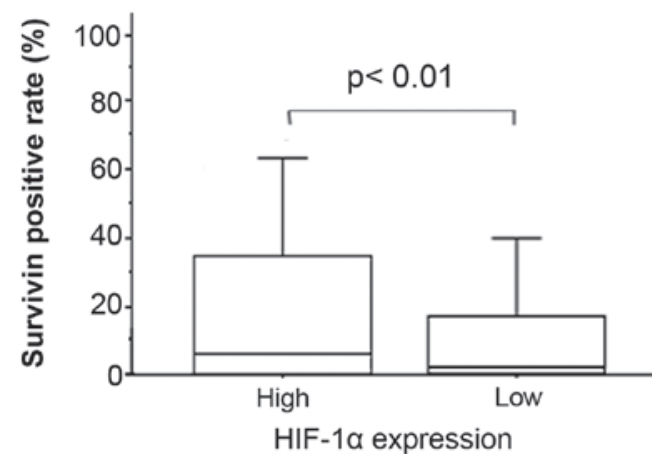

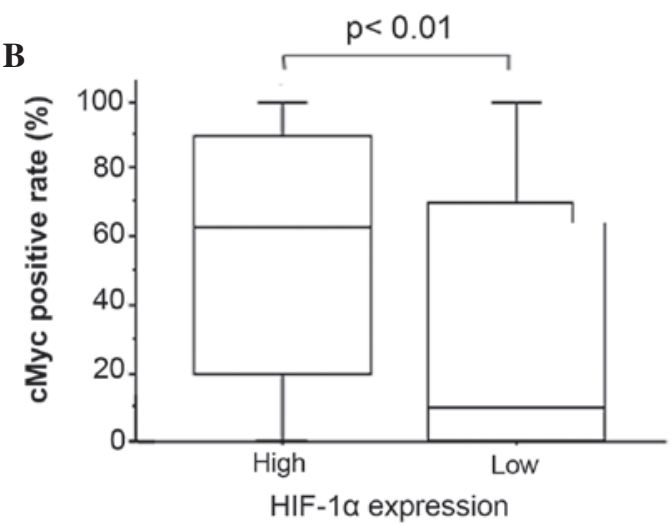

Figure 2. Survivin- and c-Myc positive cases, according to the expression of HIF-1 $\alpha$. (A) The survivin-positive rate and (B) the c-Myc-positive rate in relation to HIF-1 $\alpha$ expression. The data are presented as the mean \pm standard deviation. HIF, hypoxia-inducible factor.

cantly higher in the high-HIF-1 $\alpha$ tumors compared with the low-HIF-1 $\alpha$ tumors $(54.3 \pm 37.1$ vs. $34.5 \pm 38.2 \%$; $\mathrm{P}<0.01$; Table III; Fig. 2).

With regards to $\mathrm{Ki}-67$, the $\mathrm{Ki}-67$ proliferation index was significantly higher in the high-HIF-1 $\alpha$ tumor group compared with that in the low-HIF-1 $\alpha$ tumor group $(47.5 \pm 30.9$ vs. $34.6 \pm 32.9 \% ; \mathrm{P}=0.01$; Table III). The Ki-67 proliferation index also had significant associations with high-survivin tumors and high-c-Myc tumors: The Ki-67-positive rates for high- and low-survivin tumors were $58.1 \pm 28.8$ and $29.7 \pm 30.8 \%$, respectively $(\mathrm{P}<0.01)$, while the Ki-67-positive rates for high- and low-c-Myc tumors were $47.0 \pm 31.1$ and $30.1 \pm 32.3 \%$, respectively $(\mathrm{P}<0.01)$.
Table III. Association between HIF-1 $\alpha$ and other immunohistochemical markers.

\begin{tabular}{lccr}
\hline & \multicolumn{2}{c}{$\begin{array}{c}\text { HIF-1 } \alpha \\
\text { expression }\end{array}$} & \\
\cline { 2 - 3 } Tumor marker (\%) & High & Low & P-value \\
\hline Ki-67 & 47.5 & 34.6 & 0.01 \\
Survivin & 20.3 & 11.2 & $<0.01$ \\
c-Myc & 54.3 & 34.5 & $<0.01$
\end{tabular}

HIF-1 $\alpha$, hypoxia-inducible factor- $1 \alpha$. 


\section{Discussion}

A variety of genes are involved in tumor proliferation, invasion and metastasis. HIF-1 $\alpha$ is a transcriptional factor that controls situations, including angiogenesis, glucose metabolism and antiapoptosis. $H I F-1 \alpha$ is expected to be an important gene that cancers utilize during growth (4-7).

Survivin and c-Myc are genes that are known to be highly expressed in certain cancer types. Survivin is a member of the inhibitor of apoptosis protein family and it inhibits the activation of caspase included in the apoptotic pathway (10,13-15). c-Myc is a famous transcriptional factor that has been observed in various types of cancers. It serves a role in cell-cycle progression through the stimulation and repression of the expression of cell-cycle regulators $(17,18,22,23)$. Although the signaling pathways between HIF-1 $\alpha$, survivin and c-Myc remain to be sufficiently elucidated, certain previous reports have noted that HIF-1 $\alpha$ is a regulator of survivin and c-Myc, and also acts as their transcription factor $(15,23)$.

The present study revealed that squamous cell carcinoma, a low GGO ratio and a high SUVmax were significantly associated with HIF-1 $\alpha$ expression. These findings indicated that the solid tumors were sometimes subjected to low-oxygen conditions and expressed HIF-1 $\alpha$ to adapt to hypoxia. The pathological features of the patients also showed that positive lymphatic invasion and high tumor differentiation were correlated with HIF-1 $\alpha$ expression, indicating an association between HIF-1 $\alpha$ and tumor proliferation. Regarding the immunohistochemistry results, the present study revealed that HIF-1 $\alpha$ expression was significantly associated with the expression levels of survivin and c-Myc, indicating that HIF-1 $\alpha$ was associated with tumor proliferation and antiapoptosis in resected lung cancer. The observed correlation between HIF-1 $\alpha$ expression and the $\mathrm{Ki}-67$ proliferation index is also suggestive of the association between HIF-1 $\alpha$ and tumor proliferation.

Previous studies have identified HIF-1 $\alpha$ expression in various cancer types, and HIF-1 $\alpha$-targeted therapy has started to be applied clinically to several cancers $(24,25)$. For example, the molecularly targeted drug, everolimus, has been applied to renal cell cancer and pancreatic endocrine tumors. Everolimus inhibits mammalian target of rapamycin (mTOR), a $H I F-1 \alpha$ translation activator, and reduces the quantity of HIF-1 $\alpha$ protein. Other HIF-1 $\alpha$-targeted drugs are in clinical trials, including HIF-1 $\alpha$ small interfering RNA. Furthermore, a drug that inhibits the binding of the HIF complex to DNA (GL331, echinomycin) has been included cell-line experiments $(24,25)$. Although no HIF-1 $\alpha$-targeted therapy that has been adapted for lung cancer currently exists, these HIF-1 $\alpha$-targeted therapies are expected to provide novel treatments for lung cancer in the future. Appropriate patient selection will become a key issue when these anti-HIF-1 treatments are clinically applied to lung cancer. Subgroups of patients in which high HIF-1 $\alpha$ expression is expected may represent good candidates for these therapies, including patients of squamous cell carcinoma with positive lymphatic invasion, low tumor differentiation, a low GGO ratio and a high SUVmax.

In conclusion, the present study demonstrated that HIF-1 $\alpha$ expression was associated with tumor proliferation and antiapoptosis in lung cancer via the expression of survivin and
c-Myc. Future studies involving clinical HIF-1 $\alpha$-targeted therapy are warranted.

\section{References}

1. Semenza GL: Expression of hypoxia-inducible factor 1: Mechanisms and consequences. Biochem Pharmacol 59: 47-53, 2000.

2. Semenza GL: Targeting HIF-1 for cancer therapy. Nat Rev Cancer 3: 721-732, 2003.

3. Thrash-Bingham CA and Tartof KD: aHIF: A natural antisense transcript overexpressed in human renal cancer and during hypoxia. J Natl Cancer Inst 91: 143-151, 1999.

4. Harada H, Itasaka S, Kizaka-Kondoh S, Shibuya K, Morinibu A, Shinomiya K and Hiraoka M: The Akt/mTOR pathway assures the synthesis of HIF-1alpha protein in a glucose- and reoxygenation-dependent manner in irradiated tumors. J Biol Chem 284: 5332-5342, 2009.

5. Kaelin WG Jr: The won Hippel-Lindau tumor suppressor protein: O2 sensing and cancer. Nat Rev Cancer 8: 865-873, 2008

6. Simon F, Bockhorn M,Praha C, Baba HA, Broelsch CE, Frilling A and Weber F: Deregulation of HIF1-alpha and hypoxia-regulated pathways in hepatocellular carcinoma and corresponding non-malignant liver tissue-influence of a modulated host stroma on the prognosis of HCC. Langenbecks Arch Surg 395: 395-405, 2010.

7. Giles RH, Lolkema MP, Snijckers CM, Belderbos M, van der Groep P, Mans DA, van Beest M, van Noort M, Goldschmeding R, van Diest PJ, et al: Interplay between VHL/HIF1alpha and Wnt/beta-catenin pathways during colorectal tumorigenesis. Oncogene 25: 3065-3070, 2006.

8. Kim SJ, Rabbani ZN, Dewhirst MW, Vujaskovic Z, Vollmer RT, Schreiber EG, Oosterwijk E and Kelley MJ: Expression of HIF-1alpha, CA IX, VEGF, and MMP-9 in surgically resected non-small cell lung cancer. Lung Cancer 49: 325-335, 2005.

9. Volm M and Koomägi R: Hypoxia-inducible factor (HIF-1) and its relationship to apoptosis and proliferation in lung cancer. Anticancer Res 20: 1527-1533, 2000.

10. Mita AC, Mita MM, Nawrocki ST and Giles FJ: Survivin: Key regulator of mitosis and apoptosis and novel target for cancer therapeutics. Clin Cancer Res 14: 5000-5005, 2008.

11. Liu N, Sun Y, Zhao N and Chen L: Role of hypoxia-inducible factor-1 $\alpha$ and survivin in oxygen-induced retinopathy in mice. Int J Clin Exp Pathol 7: 6814-6819, 2014.

12. Wu XY, Fu ZX and Wang XH: Effect of hypoxia-inducible factor $1-\alpha$ on survivin in colorectal cancer. Mol Med Rep 3: 409-415, 2010

13. Chen XQ, Zhao CL and Li W: Effect of hypoxia-inducible factor-1alpha on transcription of survivin in non-small cell lung cancer. J Exp Clin Cancer Res 28: 29, 2009.

14. Shinohara ET, Gonzalez A, Massion PP, Chen H, Li M, Freyer AS, Olson SJ, Andersen JJ, Shyr Y, Carbone DP, et al: Nuclear survivin predicts recurrence and poor survival in patients with resected nonsmall cell lung carcinoma. Cancer 103: 1685-1692, 2005.

15. Brennan DJ, Rexhepaj E, O'Brien SL, McSherry E, O'Connor DP, Fagan A, Culhane AC, Higgins DG, Jirstrom K, Millikan RC, et al: Altered cytoplasmic-to-nuclear ratio of surivin is a prognostic indicator in breast cancer. Clin Cancer Res 14: 2681-2689, 2008.

16. Koshiji M, Kageyama Y, Pete EA, Horikawa I, Barret JC and Huang LE: HIF-1alpha induces cell cycle arrest by functionally counteracting Myc. EMBO J 23: 1949-1956, 2004.

17. Pelengaris S, Khan M and Evan G: c-Myc: More than just a matter of life and death. Nat Rev Cancer 2: 764-776, 2002.

18. Dang CV, Resar LM, Emison E, Kim S, Li Q, Prescott JE, Wonsey D and Zeller K: Function of the c-Myc oncogenec transcription factor. Exp Cell Res 253: 63-77, 1999.

19. Goldstraw P, Crowley J, Chansky K, Giroux DJ, Groome PA, Rami-Porta R, Postmus PE, Rusch V and Sobin L; International Association for the Study of Lung Cancer International Staging Committee; Participating Institutions: The IASLC lung cancer staging project: Proposals for the revision of the TNM stage groupings in the forthcoming (seventh) edition of the TNM classification of malignant tumors. J Thorac Oncol 2: 706-714, 2007.

20. Karetsi E, Ioannou MG, Kerenidi T, Minas M, Molyvdas PA, Gourgoulianis KL and Paraskeva E: Differential expression of hypoxia-inducible factor- $1 \alpha$ in non-small cell lung cancer and small cell lung cancer. Clinics (Sao Paulo) 67: 1373-1378, 2012. 
21. Kobayashi M, Hyang CL, Sonobe M, Kikuchi R, Ishikawa M, Kitamura J, Miyahara R, Menju T, Iwakiri S, Itoi K, et al: Intratumoral Wnt2B expression affects tumor proliferation and survival in malignant pleural mesothelioma patients. Exp Ther Med 3: 952-958, 2012.

22. Dang CV, Kim JW, Gao P and Yustein J: The interplay between MYC and HIF in cancer. Nat Rev Cancer 8: 51-56, 2008.

23. Huang LE: Carrot and stick: HIF-alpha engages c-Myc in hypoxic adaptation. Cell Death Differ 15: 672-677, 2008.
24. Semenza GL: Evaluation of HIF-1 inhibitors as anticancer agents. Drug Discov Today 12: 853-859, 2007.

25. Fujita M, Yasuda M, Kitatani K, Miyazawa M, Hirabayashi K, Takekoshi S, Iida T, Hirasawa T, Murakami M, Mikami M, et al: An up-to-date anti-cancer treatment strategy focusing on HIF-1alpha suppression: Its application for refractory ovarian cancer. Acta Histochem Cytochem 40: 139-142, 2007. 